\title{
A Spatially Intelligent Public Participation System for the Environmental Impact Assessment Process
}

\section{Lei Lei * and Brian Hilton}

School of Information Systems and Technology, Claremont Graduate University, Claremont, CA 91711, USA; E-Mail: brian.hilton@cgu.edu

* Author to whom correspondence should be addressed; E-Mail: lei.lei@cgu.edu;

Tel.: +1-909-267-4880; Fax: +1-909-793-3112.

Received: 25 March 2013; in revised form: 5 May 2013 / Accepted: 7 May 2013 /

Published: 27 May 2013

\begin{abstract}
An environmental impact assessment (EIA) is a decision-making process that evaluates the possible significant effects that a proposed project may exert on the environment. The EIA scoping and reviewing stages often involve public participation. Although its importance has long been recognized, public participation in the EIA process is often regarded as ineffective, due to time, budget, resource, technical and procedural constraints, as well as the complexity of environmental information. Geographic Information System (GIS) and Volunteer Geographic Information (VGI) have the potential to contribute to data collection, sharing and presentation, utilize local user-generated content to benefit decision-making and increase public outreach. This research integrated GIS, VGI, social media tools, data mining and mobile technology to design a spatially intelligent framework that presented and shared EIA information effectively to the public. A spatially intelligent public participative system (SIPPS) was also developed as a proof-of-concept of the framework. The research selected the Tehachapi Renewable Transmission Project (TRTP) as the pilot study area. Survey questionnaires were designed to collect feedback and conduct evaluation. Results show that SIPPS was able to improve the effectiveness of public participation, promote environmental awareness and achieve good system usability.
\end{abstract}

Keywords: GIS; VGI; public participation; environmental impact assessment 


\section{Introduction}

An environmental impact assessment (EIA) is a decision-making process that systematically evaluates the possible significant (negative or positive) effects that a proposed project action may exert on the natural, social and human environment of a particular geographic area. The assessment results are often included in a document known as an environmental impact statement (EIS). An EIS usually includes, but is not limited to, the following topics: the environmental objectives and regulations, the baseline conditions of the existing environment, the proposed project and alternatives, impact analysis on the affected environment and consequences, public comments and comment analysis, mitigations and recommendations and other monitoring measures. The EIA process consists of multiple stages, and citizens normally participate in EIA at the stage of scoping and public reviewing. The scoping stage provides an opportunity for the pubic to express what they would like the EIS to address and the reviewing stage allows the public to comment on the draft EIS before the final EIS is generated. Other name variations, such as environmental impact report (EIR), have been used; for consistency, this study uses the term "EIA" to represent similar processes and "EIS" to represent similar documents hereafter.

Although the importance of involving the public to participate in the EIA process has long been recognized [1], it is often regarded as ineffective, due to material, technical and process complexity, as well as the nature of environmental information [2]. How to improve the effectiveness of public participation in the EIA process continues to draw the attention of researchers [1]. Traditional methods for the public to participate in EIA include public meetings, telephone interviews, emails and surveys [3,4]. Information technology and geographic information system (GIS) are considered two major vehicles that have brought innovation to the conventional approaches [4]. The term "public participation geographic information systems (PPGIS)" first appeared in a GIS workshop organized by the National Center for Geographic Information and Analysis (NCGIA). The primary goal was to identify GIS solutions to empower the less privileged groups and incorporate socially differentiated local knowledge [5]. Since then, PPGIS has evolved towards the direction of leveraging GIS to engage the public in policy-making, support non-governmental organizations (NGOs), grassroots groups and community-based organizations (CBOs) [6]. Many PPGIS environmental information systems have been developed [7-9]. However, researchers pointed out that previous work often attached importance to the aspects of environmental modeling, analysis or implementation techniques and rarely discussed the design and system usability with regard to involving the public more actively and effectively in EIA [10]. According to Sieber, one of the major challenges for PPGIS is how to effectively and accurately present the available data and the results retrieved from the underlying modeling and quantitative analysis in a GIS-based environmental system such that the public would understand them correctly and be willing to participate [6].

Recently, the advancement of Internet technology and the proliferation of Web 2.0 has brought new behaviors to a geographically-enabled information society and has infused public participation with new energy. The phenomena fall into six major yet overlapping categories [11]: (1) user-generated content, which refers to digital information, such as videos, photos, blogs, news feeds and podcasts, created by the web users and normally shared with other users [12]; (2) leveraging the collective wisdom of the crowd to identify a design or solution (e.g., crowdsourcing) [13,14]; (3) large-scale data of multi-dimensional complexity that often require massive storage space and powerful database 
searching, processing and analysis capabilities; (4) participatory frameworks, which associate citizens' local knowledge and observations with geospatial footprints (e.g., an address) [11,15]; (5) prevalent virtual community and social media involvement that encourage user interaction through online platforms, such as message boards, chat rooms or social networking sites; and lastly, (6) harnessing geospatial technology to benefit non-expert users or communities [16]. With the empowerment of these evolving categories, users are more likely and willing to be engaged in generating and consuming web-based geospatial contents [17]. This, in turn, leads to another new phenomenon which has been termed "volunteered geographic information" (VGI) $[18,19]$. Researchers have also used "neogeography" [16,20,21], "cybercartography" [22] or "asserted geographic information" (in the sense that its content is asserted by its creator without citation, reference or screening of another authority) [18] to describe similar activities. For the sake of consistency, this paper will use the term "VGI" hereafter.

The growth of VGI contributes to the gathering, sharing and visualization of geographic information. Unlike the traditional top-down approach that generates or distributes paper-based or web-based geospatial contents from authoritative or professional sources (e.g., governmental agencies), VGI adopts a bottom-up approach that engages a large number of citizens and shifts the role of users from mere "data consumers to active participants and providers" of user-generated content [23]. This shift can leverage local intelligence to benefit local government, state agencies and CBOs in improving decision quality, reducing process time, promoting cost-effectiveness, maintaining transparency and legitimacy and ultimately contributing to the development of a civil society [24].

The importance of VGI in environmental areas has also been recognized by scholars. Research suggests that VGI can contribute to reflecting public environmental concerns [25], promoting environmental awareness [26], providing environmental policy makers with local and timely data [26] and expediting new public policy changes on small scales in environmental monitoring activities [27]. Particularly relevant to GIS and public participation, citizens can now access variations of VGI to contribute information located on a map through web-based mapping application interfaces [28]. For example, Werts developed a WebGIS framework to increase public participation in soil and water conservation [26]. Another example is OakMapper (http://www.oakmapper.org/) that allows people to report tree disease information and obtain an overview of the tree health status across California using an online mapping tool [29]. With the help of VGI, agencies and organizations are now able to gather geographic information with local intelligence that may not be available otherwise.

As mentioned previously, public comments are often submitted to the EIA lead agency via mail, email, phone or fax in many EIA projects. These comments consist of text mostly and the volume can grow rapidly during the draft EIS phase. After receiving the comments, agency staff need to screen, consolidate and analyze them based on the National Environmental Policy Act of 1969 (NEPA) and/or the EIA lead agency's approach and respond to each of the individual comments (NEPA §1503.4(a), http://ceq.hss.doe.gov/nepa/regs/ceq/1503.htm). In many cases, there is no effective automated mechanism for decision makers to explore and extract meaningful information from raw comments. This problem can be alleviated by data mining. Data mining is a technique that aims at automatically extracting data and discovering implicit patterns and trends from large data sets or databases [30]. Those patterns and trends often represent intelligent information related to relevance, innovativeness and interestingness. Data mining usually consists of three kinds of tasks: information retrieval, 
named-entity recognition and information extraction [31]. Spatial data mining often takes place when data mining algorithms are applied to geospatial information. Geospatial information retrieval and extraction has recently been identified by the National Geospatial-Intelligence Agency (NGA) as one of the key research areas in the next 15 years [15]. Benefits of data mining include improving data collection efficiency, reducing efforts and costs, enhancing data quality and coherence of assessments [32] and supporting good strategic identification in decision-making [33].

The primary objective of this study was to develop a spatially intelligent solution to improve the effectiveness of public participation in the EIA process. Criteria to define effectiveness are presented later in Section 5.1. The secondary objective was to leverage the solution to raise the environmental awareness of the public and contribute to the knowledge base regarding public participation in policy making in general. The research integrated GIS, VGI, social media tools, data mining and mobile technology to design a spatially enabled framework that presented and shared EIA information effectively to the public. A prototype spatially intelligent public participative system (SIPPS) was also developed as a proof-of-concept of the framework.

\section{Study Area Selection}

Since environmental issues cover a wide range of topics and various EIAs target specific environmental problems, this research selected one EIA project as a case study area and used the EIA associated environmental information to design the solution framework and the prototype system. This section reviews the selected EIA project and the problems associated with its current system.

\subsection{California Energy Problem and Study Site Selection}

This research selected the Tehachapi Renewable Transmission Project (TRTP) as the study area. TRTP was first proposed by Southern California Edison (SCE) in 2007 as part of SCE's effort to fulfill the requirements imposed by California's Renewables Portfolio Standard (RPS) and the final EIS for TRTP was completed in September 2010. RPS was initially established by the California Public Utilities Commission (CPUC) and the California Energy Commission in 2002 with the major goal of providing affordable, reliable and clean energy to meet the needs of the increasing state population in the next 20 years. The RPS program required investor-owned utilities, electricity service providers and community choice aggregators to increase procurement from eligible renewable energy resources to $33 \%$ of total procurement by 2020 . TRTP proposed to integrate new wind generation in the Tehachapi Wind Resource Area (TWRA) and would construct, operate, relocate and maintain transmission infrastructure along about 173 miles of new and existing right-of-way across Kern County, Los Angeles County, Angeles National Forest and San Bernardino County in Southern California. The proposed activities could have significant impacts on the environment, and the proposal was therefore required by NEPA to conduct an EIA. The USDA Forest Service (USFS) was the federal lead agency and the CPUC was the state lead agency. They worked collaboratively with other responsible agencies and citizens to collect information and prepare the draft and final EIS.

TRTP was selected as the prototype in this study, due to the following considerations: First, it is the first major transmission project in California being constructed specifically to access multiple renewable generators in a remote renewable-rich resource area. Second, TRTP has been a very 
controversial project since its initiation. Compared to other SCE renewable energy transmission projects, it received more public comments than any other projects listed on SCE's website (http://www.sce.com/ PowerandEnvironment/Transmission/ProjectsByCounty/projects-by-county.htm). The EIA process for TRTP was lengthy and involved many back-and-forth conversations and negotiations among agencies, SCE and the public. The combination of these factors makes TRTP a great prototype case for this study while maintaining the generalizability of the findings.

\subsection{Existing Website Problems}

CPUC has an existing FTP website to host the TRTP EIA documents and public comments (ftp://ftp.cpuc.ca.gov/gopher-data/environ/tehachapi_renewables/TRTP.htm). This website is, however, ineffective in multiple senses. First, it is primarily a static document repository with a flat file structure and overwhelming data. It does not adopt any available VGI technology to alleviate the cognitive difficulty that decision makers and public users might encounter. All the project maps are static PDF files and none of their potential impacts are displayed directly on the maps. Ideally, EIA should be a comprehensive interactive process beyond a mere documentation warehouse. However, citizens played the role of a passive recipient on this website rather than an active participant and could hardly interact with either the decision makers or other citizens. Second, the comment submission process is not automated. Raw public comments were collected via fax, phone, email and mail or at the public meetings using physical forms and each comment is listed as a single PDF file online. If a user wants to see the comments, they would have to laboriously click and open each PDF one by one. Third, the website has a disconnected workflow, and the components on the website fail to support each other. For example, the comments cannot be directly viewed on the map viewer and the map viewer never presents any demographic information about the participants, and thus, it is difficult to obtain the overall EIA status and understand the spatial distribution of public participants. Overall, the existing website was not designed in a manner to engage the public effectively. The framework proposed in this study can alleviate those problems.

\section{Conceptual Framework Design}

This section presents a spatially intelligent conceptual framework that integrates GIS, VGI, data mining and mobile technology to improve the effectiveness of public participation in EIA. The framework is designed for two intended groups of users: (1) citizens who view the environmental information, review other users' comments, identify possible alternatives or potential impacts and provide their own feedback to the EIA lead agency; (2) decision makers such as agency staff who not only access all the functionality available to citizens, but also have the task of analyzing and responding to comments, evaluating project alternatives and consequences, generating status reports and making final decisions on projects.

The framework includes five components: a spatial component, an analysis component, a comment component, a data mining component and a mobile component. The first four components are designed to be accessible to users through a web browser on a personal computer and the mobile component provides an additional dimension for the public to participate through mobile devices. 
Figure 1 shows the concept of operation for the proposed framework. In Figure 1, each green box represents a component and each pink box represents the output from the corresponding component.

Figure 1. Conceptual framework for SIPPS.

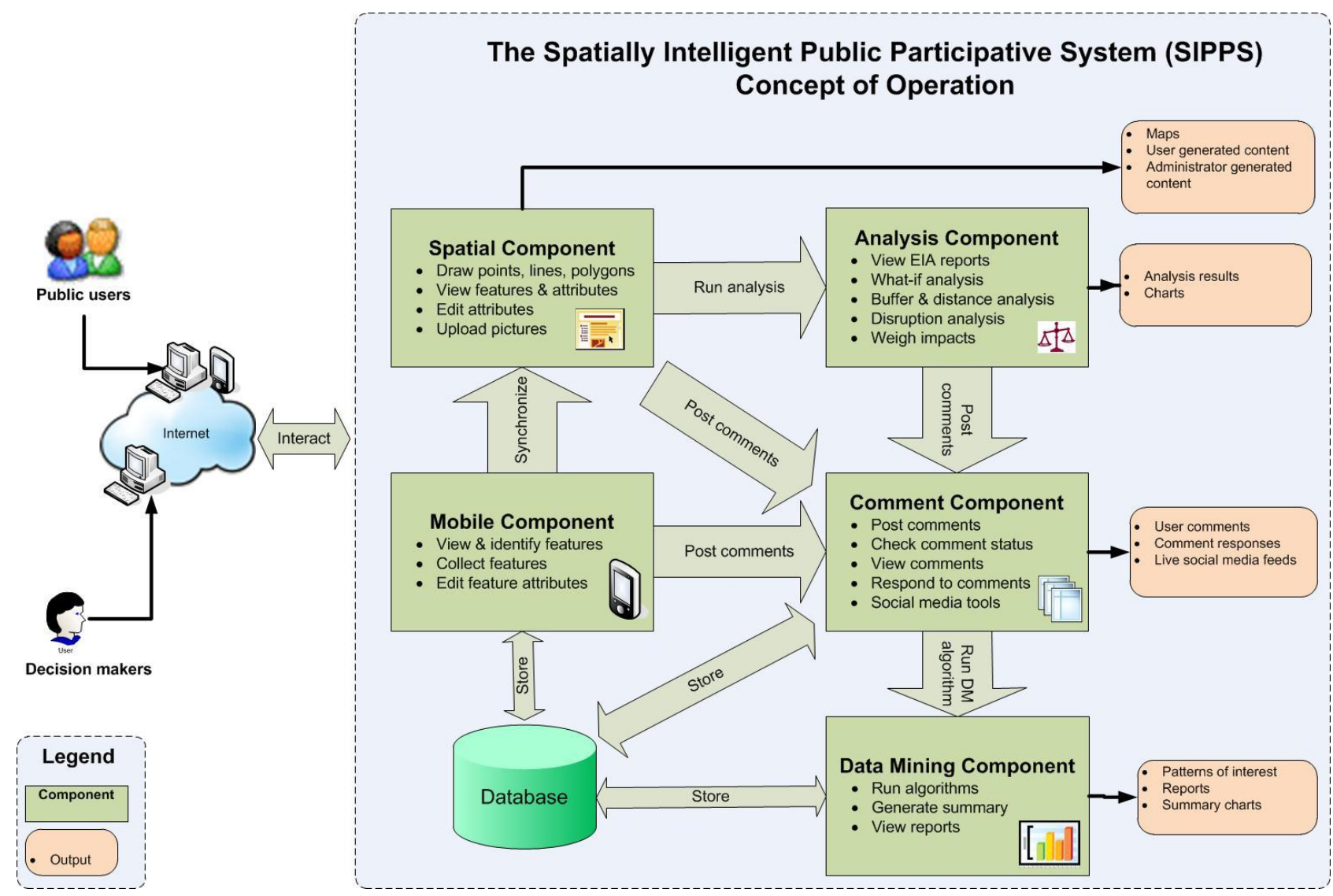

Each component has its unique capabilities:

- The spatial component visualizes the EIA data on a map viewer to assist scoping and planning and distributes the EIA geospatial information through a graphical user interface (GUI) to improve public outreach. This component will allow a user to dynamically navigate maps, view and toggle environmental information layers related to an EIA project, locate geographic objects (e.g., a proposed power station) on the map and review object attributes (e.g., the height of a power tower) in a pop-up window. One of the most critical activities in the EIA scoping phase is to identify potential alternatives [34]. Adequate consideration of various alternatives can mitigate possible bias, improve process transparency, increase stakeholders' confidence and contribute to a balanced decision-making process. With the help of the spatial component, stakeholders will be able to assist in the identification of potential impacts using feature editing tools and maps from the area (e.g., a public user may use the tool to draw a new polyline in a different place on the map to indicate another possible electric power transmission segment that would meet the same purpose and need for the TRTP project).

- The analysis component supports planning and discloses further intelligence that may not be otherwise obvious to increase environmental awareness. The analysis component will enable target users to perform scenario analysis and what-if analysis, weigh environmental factors for different 
project alternatives and outcomes and contemplate how a selected location they care about is spatially related to and potentially affected by the proposed EIA activities such as the construction of power transmission lines.

- The comment component provides a platform for comment collection, review and management. This component will allow a public user to review existing comments posted by other citizens, interact with other user comments, rate comments and post new comments specific to geographic locations on the map. Comments are no longer limited to text, but can also be user-generated content, such as PDF files, pictures, audio files or videos that can be uploaded to associate with comments on the map. This component will also facilitate decision makers to categorize comments, update comment status (e.g., status for submitted, reviewed and responded comments), respond to comments and review the spatial and temporal relationship among comments to obtain a holistic view. In addition, social media tools (e.g., YouTube, Flickr and Twitter) are included in the comment component to facilitate information sharing. With the increasing influence of VGI, information from virtual communities and social media networks becomes an important part of local intelligence and contributes to the aggregation of web maps and user-generated content. This part in the component will retrieve live feeds that contain keywords about the selected EIA project from YouTube, Flickr and Twitter and display the feeds dynamically with their spatial footprints on the map viewer. In this way, users can easily access the component to discover project events and activities through social media posts.

- The data mining component will use data mining algorithms such as clustering analysis to support comment analysis. By reviewing the results and graphs generated in data mining, decision makers will be able to have a better understanding about the micro-culture and composition of the local community, classify diverse interests and concerns and identify potential patterns and underlying issues that may not be easily seen through pure textual files. In this way, fairness and trust is enhanced.

- The mobile component will engage the public through another dimension. With the help of the mobile component, public users will be able to use a mobile platform to view the proposed EIA activities, perform basic map navigation, identify geographic objects and their attributes, review and post comments and associate the user-generated content such as a mobile picture taken via their mobile camera to their comments.

\section{Prototype Development}

Based on the conceptual framework presented in Section 3, a web-based application prototype system was developed as a proof-of-concept. The development process consisted of two stages: data collection and processing and application implementation.

\subsection{Data Collection and Processing}

Two types of data were collected in this study: spatial data and public comments. The following spatial data were gathered in the context of the TRTP project: basemaps and demographic digital maps that cover the project impacted areas, spatial locations of the TRTP power transmission segments and substations, spatial relationships such as buffers and viewsheds of the project activities in relation to 
the surrounding environment, and other publicly available spatial information such as soil or natural resources that were identified in the TRTP EIA scoping phase. In this study, the basemaps and demographic maps were retrieved from the map services posted in ArcGIS Online (www.arcgisonline.com). The TRTP power segments and substations were manually digitized as spatial features based on the static maps provided in the final TRTP EIS using ArcInfo 10.0. Spatial relationships were generated based on the power line segments using ArcInfo 10.0 Geoprocessing toolboxes. Raw data of other supportive spatial information were downloaded from publicly accessible government geospatial data portals. They were initially in heterogeneous formats and were then transformed to a consistent spatial reference such that they can be overlaid and displayed correctly within one single dynamic map viewer. A geodatabase was also designed in the study to capture the functional artifacts, workflows and data constraints.

The comment data were obtained from two sources: an Excel spreadsheet containing 233 public comments with user addresses and additional information was obtained from SCE; the PDF comment files were downloaded from the existing TRTP EIA website. As previously mentioned, many of the PDF files listed on the website were scanned from hand-written physical forms. This makes it difficult for machines to recognize and for users to review. To solve this problem, the comment data were cleaned, geocoded and migrated to the geodatabase designed for this study.

\subsection{Application Design and Implementation}

During the design of the application prototype, this study initially created several high-level use cases, sequence diagrams and mockup wireframes for the conceptual framework. Feedback was collected from a small focus group, and the GUI was refined in several iterative cycles before the design was finalized. The prototype application was eventually implemented using a free JavaScript API template downloaded from Esri's Local Government Resource Center (http://localgovtemplates2.esri.com/ MapsAndApps/). Additional technology, including ArcGIS Server 10.0 and SQL Server 2008 Standard R2 were utilized for map service publishing and geodatabase configuration. The prototype application is currently hosted on a virtual machine at Claremont Graduate University (http://134.173.236.123/PublicInfoCenter/default.htm).

For the five components outlined in the conceptual framework, the spatial component, the comment component and the analysis component were instantiated on the application end user interface (Figure 2 shows the instantiation for each of them); the data mining component was made available through the backend geodatabase and geoprocessing tools; the mobile component was implemented through a mobile project created in ArcGIS Mobile 10.0 and configured with the EIA project spatial data. The user guide is also available through the help icon in the application.

\section{Evaluation and Survey Design}

After the application system was developed, an evaluation was conducted to determine if the expected research goals were achieved. This section addresses the evaluation criteria, the survey design and distribution process. 
Figure 2. Examples of the five components in SIPPS. (a) Spatial component example: a public user can select a basemap (e.g., population density) from six options and review it with other Environmental Impact Assessment (EIA) project information; (b) analysis component example: a user can view multiple buffer rings on the map and click on a location within the buffer to find out the distance from proposed project activities; (c) comment component example: each red circle on the map represents a public comment; a user can click red circles to review the comments submitted by others; (d) comment component example: a user can submit a new comment with a picture attachment; (e) comment component example: relevant live feeds from YouTube, Twitter and Flickr are retrieved dynamically and displayed on the map; (f) mobile component example: a public user can review EIA project data and post comments using a mobile device.

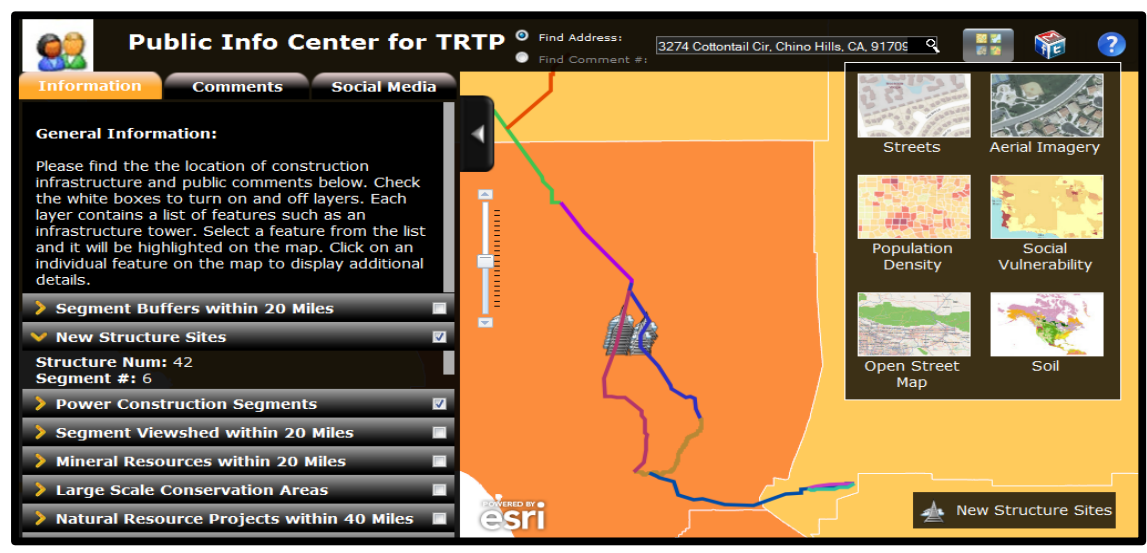

(a)

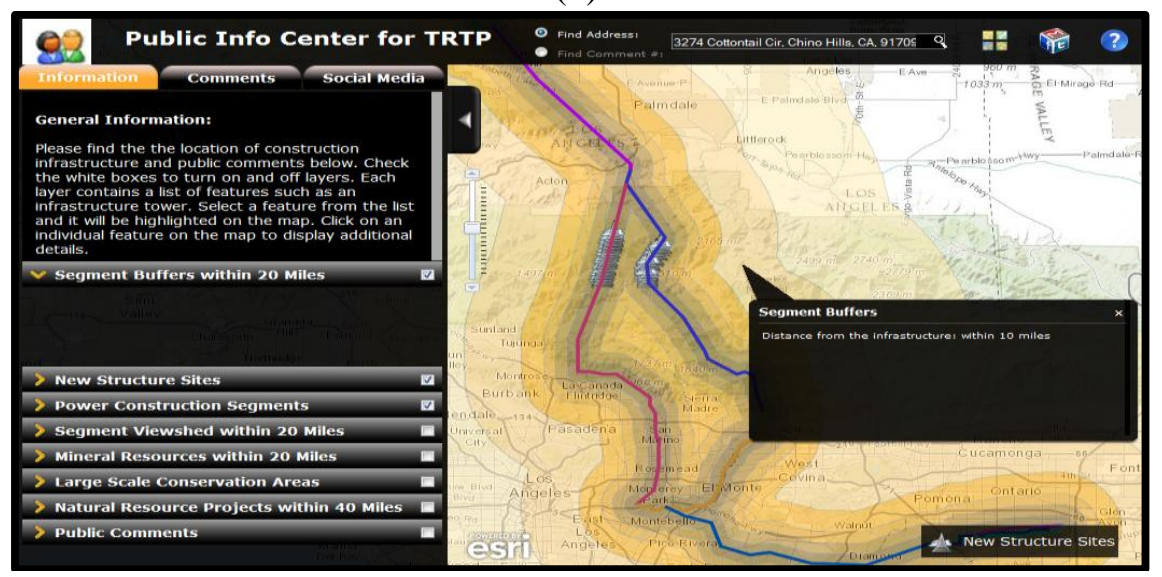

(b)

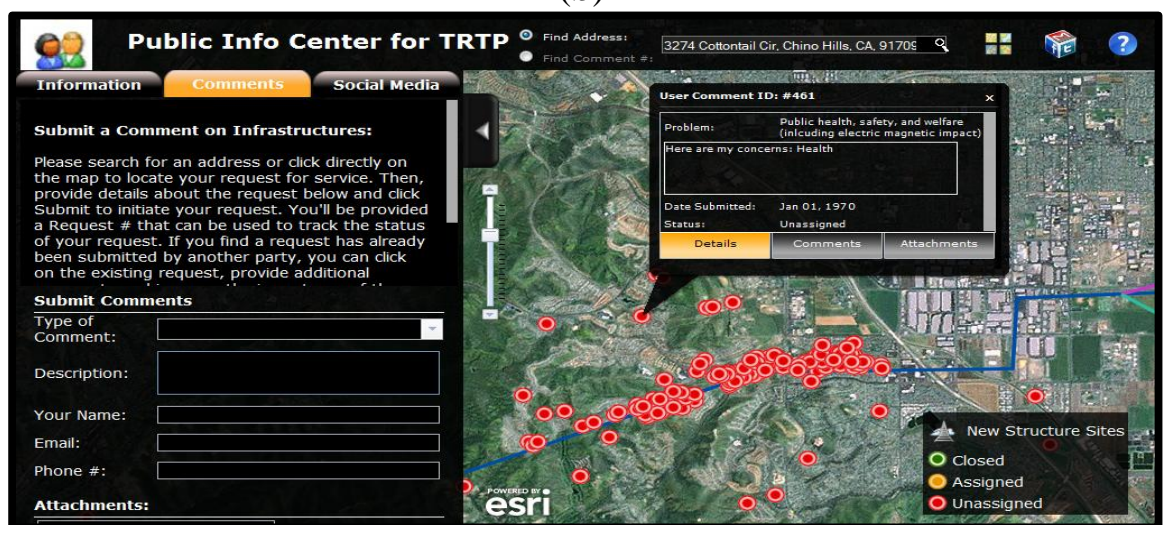

(c) 
Figure 2. Cont.

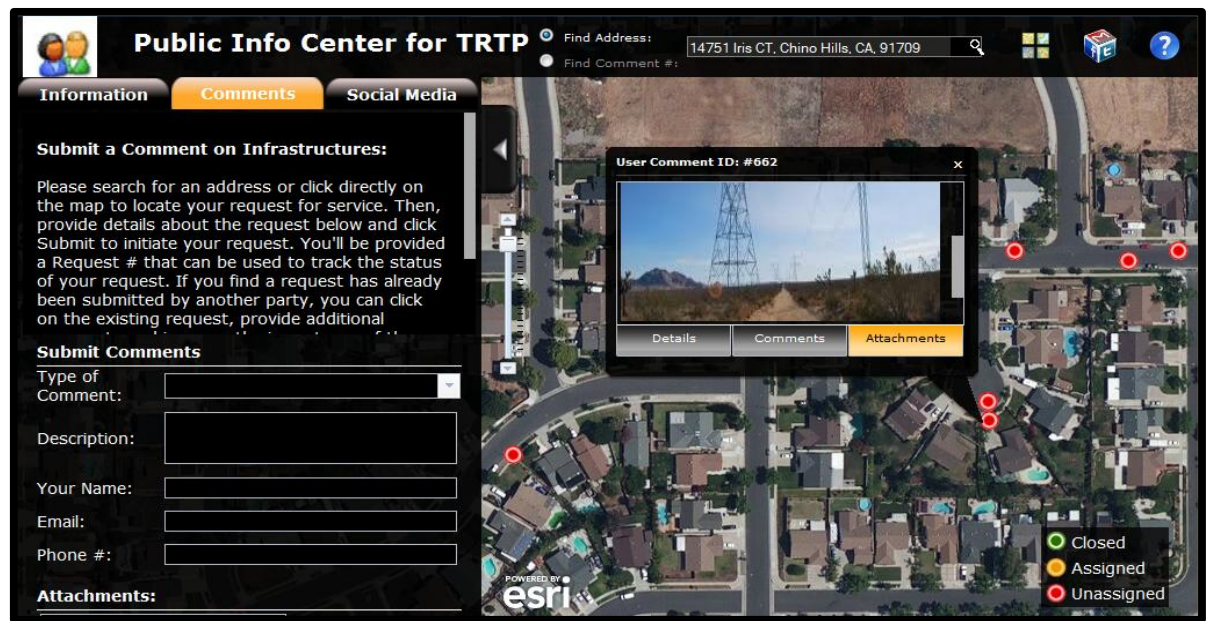

(d)

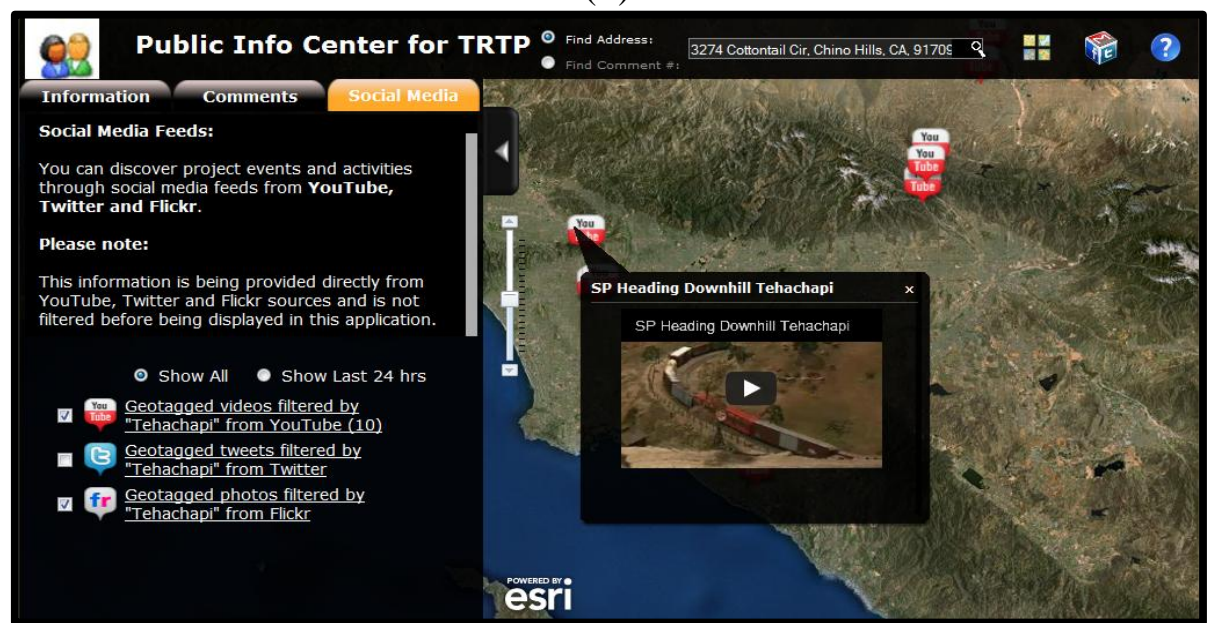

(e)
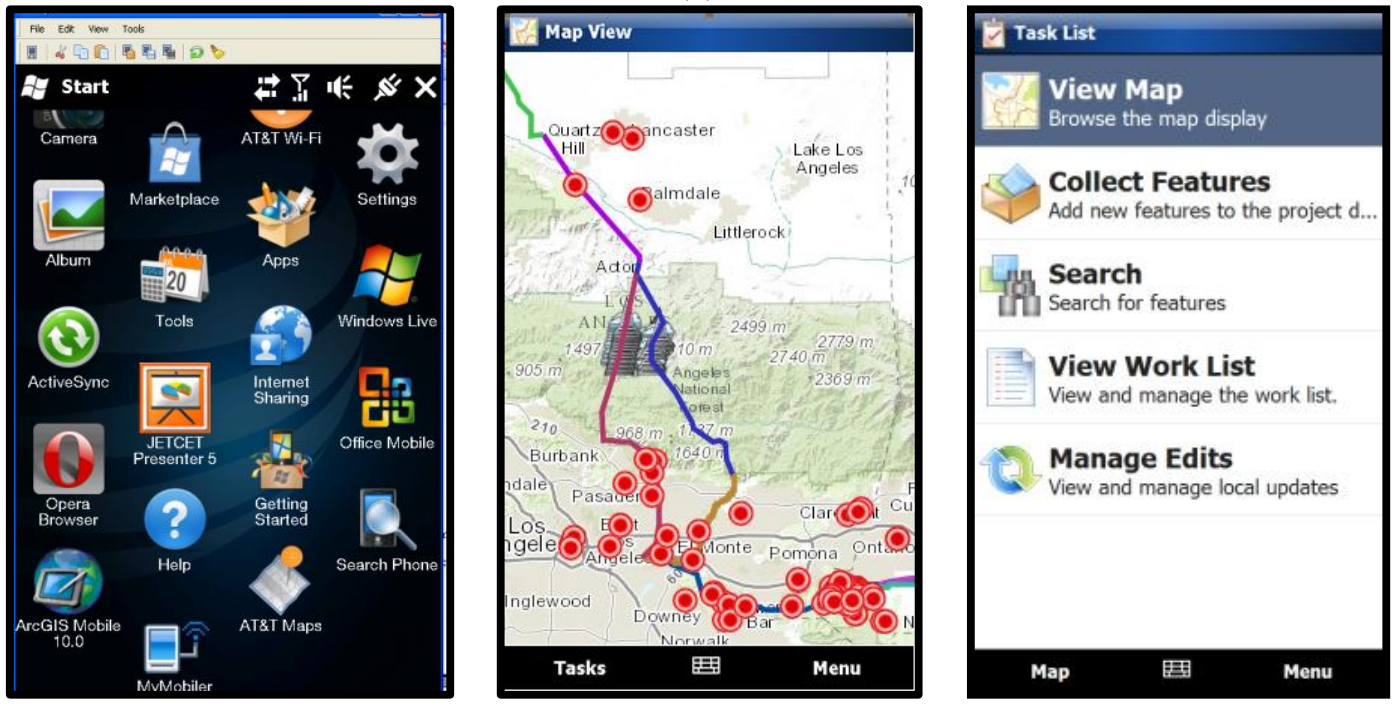

(f)

\subsection{Evaluation Criteria}

The term "public participation" has various definitions depending on the areas and context [35], but they all touch upon three distinct, yet interrelated, aspects of public rights: (1) the right of "access to 
information", (2) the right of "participation in decision-making" and (3) the right of "access to justice" [36]. Evaluation of the effectiveness of public participation can be difficult. Previous literature points out that outcome and evaluation comprise two of the least understood aspects of PPGIS and that metrics of PPGIS effectiveness have not been explored extensively by researchers [6]. Definitions of effectiveness also vary. This study followed the definition outlined by Del Furia and Wallace-Jones: "public involvement is effective when the goals of involving the public in the EIA procedure are satisfied" [1] (p. 460).

This study considered three aspects when evaluating the effectiveness of the prototype system: (1) the effectiveness of the prototype system in engaging public participation compared to the traditional methods such as email and physical meetings; (2) the empowerment capability of the system in educating the general public and promoting their environmental awareness; (3) system usability.

In selecting the indicators for evaluating the effectiveness of public participation in EIA, this study considered three models from the literature. The first was proposed by Del Furia and Wallace-Jones [1]. The model suggested that the indicators chosen to evaluate the effectiveness of public participation in EIA should be directly observable, objectively measurable or consist of evidence indicating that public participation is pursued towards the goals of understanding the perception of proposed activities and reaching consensus. Four themes were identified to influence the effectiveness of public participation in EIA: the nature of the public involved, the amount of power the public is attributed in the decision-making process by the techniques and methods used, the stage when the public is involved in the procedure and the ability to manage conflict. The second model considered by this study is De Steiguer's framework that evaluated the effectiveness and acceptability of the public participation process and included empowerment as a major factor in evaluating the effectiveness [37]. The framework was based on four criteria: accessibility, fairness, comprehensibility and empowerment. Thirdly, the analytical strategic environmental assessment (ANSEA) framework was considered by the study, because it presented a methodology to evaluate the decision-making process and has been recognized as a potential paradigm shift that drove environmental assessments to focus on analyzing decision processes rather than the environmental consequences of decisions [38]. ANSEA criteria included comprehensiveness, timeliness, transparency, participation and credibility [38]. In addition, since a web-based prototype application was developed to assess the concept of the research framework and was used as a platform to collect user feedback, the study also considered system usability as part of the evaluation criteria. The System Usability Scale (SUS) was selected to evaluate the usability of the prototype system because it provides a high-level subjective view of usability and is often used in comparing and evaluating usability between systems [39]. SUS generally consists of ten questions on a Likert scale of 1-5 and generates a single final score on a scale of 0-100. The final score represents the overall usability of a system, and a higher score usually indicates better system usability.

\subsection{Survey Design and Distribution}

Based on a combination and transformation of the indicators and evaluation criteria outlined previously, a survey questionnaire was designed to collect user feedback. The survey includes a consent form, a brief introduction about the research objective and the TRTP project background and four major sets of questions. The four question sets include: (1) Basic demographic information of the 
survey participants, which can be used later to analyze user characteristics, background and potential segmentation. (2) A series of scenarios and tasks that comprise the main component of the survey. The purpose is to help participants understand system functionality and evaluate the system more accurately. Each scenario includes two parts: a step-by-step text description of a function in the context of why it is useful and when it could be used and a diagram that demonstrates the workflow for users to perform the function. After reading each scenario, a participant was asked to complete a task related to their own situation (e.g., searching for a home address) and answer a few questions to evaluate the system. A user scenario example is provided in Figure 3. (3) Ten SUS questions to measure system usability. (4) Optional questions that may help to improve the system design in the future. Subjects were asked to type text comments on particular functionality, the overall user experience and potential improvements that they would expect the system to provide.

Figure 3. An example of a user scenario in the survey.

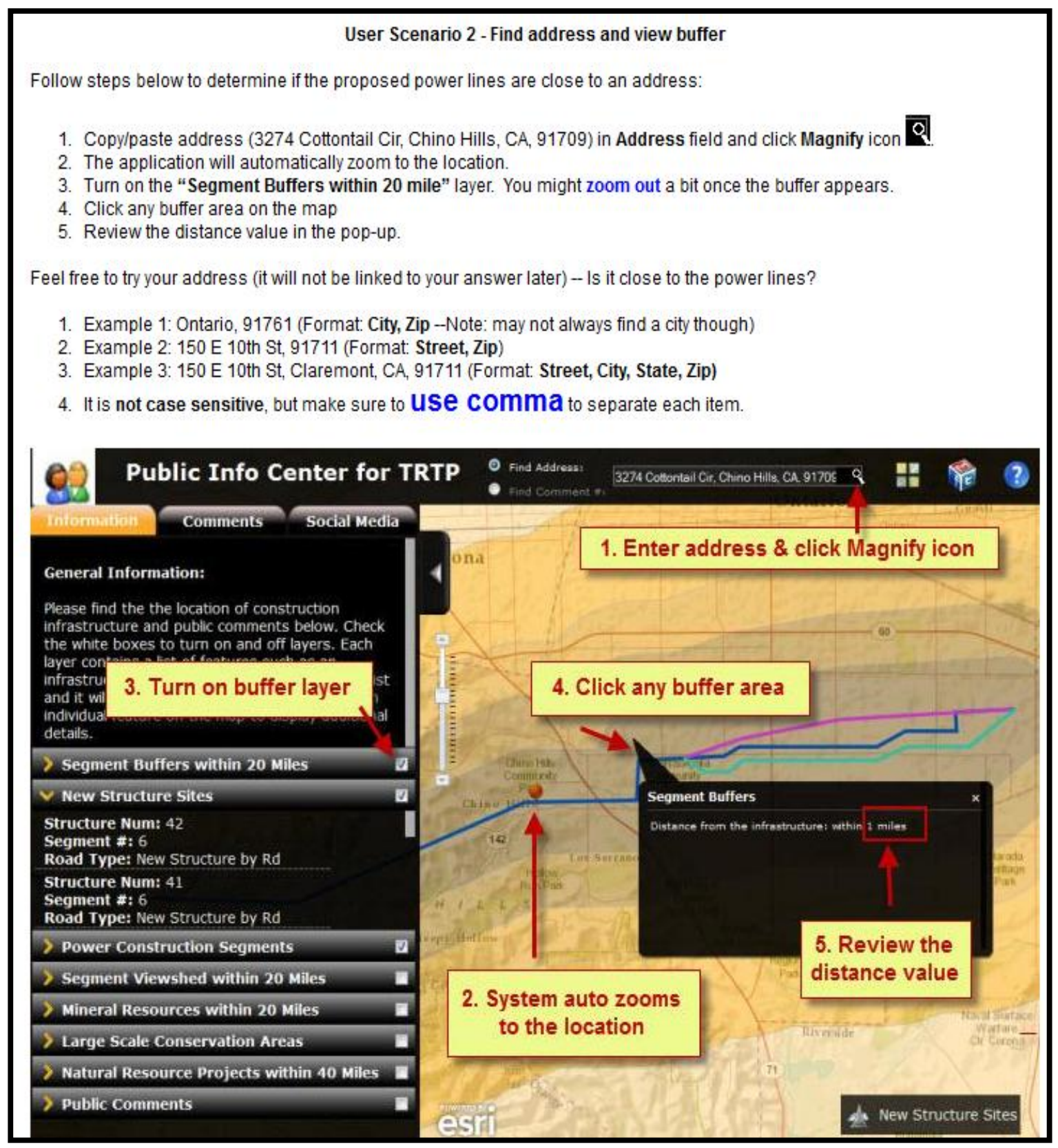


The survey was made available using an online survey tool-Qualtrics. To recruit general public users, the study selected students and staff at Claremont Graduate University (CGU) and members of the Los Angeles Chapter of the Sierra Club on a random basis. Email requests, including the link to the online survey questionnaire, were sent out to the campus server list to recruit participants. The research team also attended several classes in fall 2012 to present the study to students. In each class attended, an overview presentation about the research problems, a demonstration of the existing TRTP website and the new prototype system and a Q \& A session were provided before the participants started the survey. The online survey link was also posted on the Facebook Page of the Sierra Club in Los Angeles to solicit feedback (after receiving consent from the Sierra Club). Participation was voluntary and confidentiality of participants was ensured.

\section{Results and Analysis}

The study received 97 responses through the online survey questionnaire. Out of the 97 respondents, 12 of them only finished the demographic questions, but not the scenario questions. Therefore, they were excluded, due to incompleteness, and the analysis below is primarily focused on the remaining 85 valid complete responses. Answers in some of the questions were re-coded so that the order or the content of the survey answers would be more meaningful. The sections below present the feedback and findings discovered from the survey conducted with public users.

\subsection{Results for Demographic Questions}

This section presents the results for the demographic questions. Age: $70 \%$ of the participants were younger than 30 , and only $2 \%$ were older than 56 . Gender: $67 \%$ of the respondents were female, and $33 \%$ were male. In terms of educational level, $98 \%$ of the participants held graduate degrees or were pursuing graduate degrees. When asked about their confidence level in using computers and the Internet, $96 \%$ of the participants felt confident or very confident.

Since GIS and VGI are two of the major technologies used in this study, previous GIS experience and social media usage were regarded as factors that could impact user evaluation of the prototype system. The survey results showed that $71 \%$ of the respondents had heard about GIS before. When asked the question "How often do you use social media tools, such as Facebook, Twitter or Flickr", $80 \%$ indicated daily usage. As previously suggested, the sample population in this study consisted of a young generation with higher education and confidence in computers and use of the Internet. Those characteristics largely explain why daily usage of social media tools was selected as the dominant answer. Again, statistics indicate that a web-based information system with VGI and social media elements embedded can better suit the needs of this generation by providing equitable and immediate data access using limited resources [26].

Since the research is related to EIA, the participants were asked to rate their familiarity with the basic EIA process. The result shows that $74 \%$ of the respondents were not familiar with the basic process of EIA. This reflects a pressing need to educate the general public on the EIA process, which is also one of the objectives of this study. Furthermore, when asked the primary reason to not participate in an EIA, $68 \%$ of the subjects selected that they were unaware of when and where to participate in an EIA, and $21 \%$ chose that they did not have time to participate (see Figure 4 ). In the 
"Others (specify)" option, six participants answered that they did not know what an EIA was and two indicated that they had never been asked to participate in an EIA. Again, the responses reflect inadequate information distribution and dissemination in the EIA process and suggest that information accessibility and time efficiency are two major factors that need to be improved towards promoting public participation and environmental awareness.

Figure 4. Frequency table for Question 8: If you do not want to participate in an EIA, what is the primary reason (check all that apply)?

\begin{tabular}{|c|l|c|c|}
\hline$\#$ & Answer & Response & $\%$ \\
\hline 1 & Distance & 10 & $12 \%$ \\
2 & Time & 18 & $21 \%$ \\
3 & Inconvenience & 13 & $15 \%$ \\
4 & Unaware when/where & 58 & $68 \%$ \\
5 & Technical challenge & 3 & $4 \%$ \\
6 & Others (specify) & 13 & $15 \%$ \\
\hline
\end{tabular}

\subsection{Results for Scenario Questions}

Table 1 provides a summary of the descriptive statistics for all the scenario questions in this survey. Note that scenario questions were designed on a Likert scale of $1-4$, with 1 being "strongly disagree" and 4 being "strongly agree". The "neutral" option was purposely omitted, as the study wanted to encourage the respondents to make a specific choice. In Table 1, Question 16 (willingness to participate), 20 (transparency), 23 (willingness to comment), 28 (information accessibility) and 29 (effectiveness in promoting environmental awareness) depict a mean value greater than or equal to 3.0. This indicates that the survey respondents on average agreed that the prototype system developed for this study improved the effectiveness of public participation in these aspects.

Table 1. Descriptive statistics for the scenario questions.

\begin{tabular}{|c|c|c|}
\hline Scenario Questions & Mean & Std. Deviation \\
\hline $\begin{array}{l}\text { 10. The power segments information is useful to me in understanding } \\
\text { the project. }\end{array}$ & 2.44 & 0.763 \\
\hline 11. Viewing the buffer information helps me to understand the project. & 2.75 & 0.722 \\
\hline 12. Viewing the viewshed information helps me to understand the project. & 2.73 & 0.697 \\
\hline $\begin{array}{l}\text { 13. The layers information helps me to understand the project and its } \\
\text { potential impact. }\end{array}$ & 2.88 & 0.680 \\
\hline $\begin{array}{l}\text { 14. Viewing the Social Vulnerability Index Map helps me in understanding } \\
\text { the potential impact of the project. }\end{array}$ & 3.00 & 0.690 \\
\hline $\begin{array}{l}\text { 15. Reviewing my neighbors' comments improves my understanding about } \\
\text { the project. }\end{array}$ & 2.99 & 0.645 \\
\hline $\begin{array}{l}\text { 16. Knowing that I can review my neighbor's comments makes me more } \\
\text { willing to participate in the commenting process. }\end{array}$ & 3.07 & 0.632 \\
\hline $\begin{array}{l}\text { 17. Knowing that I can share my comments with the public will promote } \\
\text { my participation in the project. }\end{array}$ & 2.96 & 0.715 \\
\hline
\end{tabular}


Table 1. Cont.

\begin{tabular}{|l|c|c|}
\hline \multicolumn{1}{|c|}{ Scenario Questions } & Mean & Std. Deviation \\
\hline $\begin{array}{l}\text { 18. Compared to the old system, this application helps me interact with } \\
\text { other public citizens. }\end{array}$ & 2.89 & 0.598 \\
\hline $\begin{array}{l}\text { 19. Compared to the old system, I am more willing to mention or share this } \\
\text { application with my family and friends. }\end{array}$ & 2.86 & 0.620 \\
\hline $\begin{array}{l}\text { 20. Sharing comments will improve the transparency of the project } \\
\text { EIA process. }\end{array}$ & 3.19 & 0.607 \\
\hline $\begin{array}{l}\text { 22. I am more willing to submit my comments using this application than } \\
\text { using emails. }\end{array}$ & 2.81 & 0.699 \\
\hline $\begin{array}{l}\text { 23. I am more willing to submit my comments using this application than } \\
\text { attending physical meetings. }\end{array}$ & 3.28 & 0.750 \\
\hline $\begin{array}{l}\text { 24. I feel more flexible in expressing my ideas on the proposed project } \\
\text { using this application than using emails. }\end{array}$ & 2.84 & 0.769 \\
\hline $\begin{array}{l}\text { 25. I will save more time in the EIA participation process using the } \\
\text { application than using email. }\end{array}$ & 2.93 & 0.784 \\
\hline $\begin{array}{l}\text { 26. The information retrieved from the social media network improves my } \\
\text { understanding about the project. }\end{array}$ & 2.78 & 0.713 \\
\hline $\begin{array}{l}\text { 27. Including the social media tools in the application makes me more } \\
\text { willing to participate in the project. }\end{array}$ & 2.78 & 0.822 \\
\hline $\begin{array}{l}\text { 28. Compared to an FTP site, I am more able to access the TRTP } \\
\text { information with this website. }\end{array}$ & 3.00 & 0.673 \\
\hline $\begin{array}{l}\text { 29. I think a website like this will be effective in promoting } \\
\text { environmental awareness. }\end{array}$ & 3.07 & 0.651 \\
\hline
\end{tabular}

A correlation analysis was also conducted on the scenario questions. A selection of findings at the significance level of $p<0.01$ are presented:

1. Questions 11, 12, 28 are all positively correlated to Question 25. Questions 11 and 12 ask if providing buffer and viewshed information helps public users to improve their understanding about the EIA project. Question 28 compares information accessibility between this prototype website and the old TRTP project site, and Question 25 asks if using the new system will save more time than email for a citizen to participate in the EIA process. The interpretation is that the respondents agreed that a web-based application with better information accessibility and presentation was likely to save them more time than emails in their EIA participation process. As previously shown in Figure 4, 68\% of the respondents did not know where and when an EIA took place and $21 \%$ selected time as the primary reason to not participate in EIAs. This suggests that the traditional participative methods failed to deliver satisfactory information accessibility and time efficiency to the public users. With the old TRTP system, it was time consuming for the public users to explore the lengthy EIA documents to obtain the specific information they look for; with emails, they had to describe their particular situations in abstract text. On the contrary, with the help of the new system, participants can now easily review digital maps to capture a quick snapshot of the most concerned topics or locations and then submit comments by simply clicking their concerned location on the map and filling out the comment form electronically. Again the correlation suggests that the prototype system has improved the information accessibility and time efficiency and, thus, the effectiveness of public participation. 
2. Questions 12 and 26 are positively correlated to Question 28. Questions 12 and 26 are related to providing viewshed information and social media feeds to public users, and Question 28 compares information accessibility of the new system with that of the original project website. As previously mentioned in Section $6.1,80 \%$ of the participants reported daily usage of social media tools. Those tools can be a major information intake source in the user's daily information ingestion pattern; reading social media information may even become a habit. Literature also suggested that many public service activities and environmental agencies are currently faced with the challenge of budget cuts and personnel reduction, which led to a limited public outreach [26]. A more active virtual community enabled by VGI and social media tools is able to mitigate the burden on public outreach and benefit data collection and information dissemination. Since the original TRTP EIA project site does not provide any information such as viewshed and social media feeds to the public users, including this additional information in the new system fits the daily information absorbing pattern of the participants and, thus, improves information accessibility by providing instantaneous data access in the EIA process.

- Question 14 is positively correlated to Question 27 at the $p<0.01$ level and to all of the other scenario questions at the $p<0.05$ level. Question 14 asks whether viewing the Social Vulnerability Index Map is helpful for participants to understand the potential impact of the project. Social vulnerability refers to sensitivity to the exposure, due to characteristics such as age, low income, disability or home value [40]. This index helps to identify the areas of relatively greater potential social economic impact from disaster or hazards on a county or state level. The strong correlation between Question 14 and all other scenario questions can be an indication that there is a concern for the EIA project's social-economic impacts on people's perception towards risks and hazards surrounding them. Therefore, providing the public with this information addresses this concern and will motivate people to participate in EIA projects.

- Questions 15-19 and 26 are all pertinent to sharing and interaction (through reviewing neighbor comments, posting new comments, reaching out to family and friends or social media tools), and they are positively correlated as well. This is an indication that providing the public with the capability to review and share information in an interactive manner is an effective way to improve public participation.

3. Questions 23 and 24 are positively correlated to Question 27. Questions 23 and 24 compare flexibility and the comment submission method of the new system with the traditional public participative methods (email and physical meetings), and Question 27 asks if including the social media tools in the application increases user willingness to participate in the project. The interpretation is that the users who agreed that including social media tools increased their willingness to participate were more likely to agree that the new system was better than email or physical meetings for them to participate in EIA. This interpretation again indicates that including social media tools may promote user preference of the prototype over the traditional participative methods and, thus, boost public participation in the EIA process. 


\subsection{Results for SUS Questions}

In the SUS analysis, the odd-numbered questions are phrased to describe system strengths, while the even-numbered questions are phrased to describe system weakness, and as a result, the mean value for the odd-numbered questions (Q31,33,35,37,39) should be reviewed differently than that of the even-numbered questions (Q32,34,36,38,40): For the odd-numbered questions, a higher mean value indicates better system usability; for the even-numbered questions, a lower mean implies less user difficulties with a system (i.e., better system usability). Table 2 shows the frequency summary of the answers to the SUS questions. It is broken down into two parts: on one hand, the mean values for all the odd-numbered questions are over 2.8, and the mean values for Questions 33, 35 and 39 are over 3.0. These scores represent positive signs of system usability; the respondents agreed that the prototype system was easy to use (Q33), functionally well integrated (Q35) and built up their confidence in the system (Q39). On the other hand, two observations are noticed for the even-numbered questions: (1) more respondents disagreed than agreed that the new system required technical support (Q34), was inconsistent (Q34) or cumbersome to use (Q38). This is another indication of achieving good system usability. (2) Regarding the complexity of the system (Q32) and that one needed to learn a lot before continuing using the system (Q40), the number of respondents who disagreed and agreed on each side was about the same.

Table 2. Frequency summary of the answers to system usability scale questions.

\begin{tabular}{|l|c|c|c|c|c|c|c|}
\hline \multicolumn{1}{|c|}{ Question } & $\begin{array}{c}\text { Strongly } \\
\text { Disagree }\end{array}$ & Disagree & Neutral & Agree & $\begin{array}{c}\text { Strongly } \\
\text { Agree }\end{array}$ & $\begin{array}{c}\text { Total } \\
\text { Responses }\end{array}$ & Mean \\
\hline $\begin{array}{l}\text { 31. I think that I would like to } \\
\text { use this system frequently. }\end{array}$ & 11 & 19 & 33 & 20 & 2 & 85 & 2.8 \\
\hline $\begin{array}{l}\text { 33. I thought the system was } \\
\text { easy to use. }\end{array}$ & 6 & 13 & 27 & 34 & 5 & 85 & 3.22 \\
\hline $\begin{array}{l}\text { 35. I found the various } \\
\text { functions in this system were } \\
\text { well integrated. }\end{array}$ & 2 & 6 & 26 & 47 & 4 & 85 & 3.53 \\
\hline $\begin{array}{l}\text { 37. I would imagine that most } \\
\text { people would learn to use this } \\
\text { system very quickly. }\end{array}$ & 8 & 27 & 19 & 29 & 2 & 85 & 2.88 \\
\hline $\begin{array}{l}39 . \text { I felt very confident using } \\
\text { the system. }\end{array}$ & 6 & 21 & 29 & 24 & 5 & 85 & 3.01 \\
\hline $\begin{array}{l}32 . \text { I found the system } \\
\text { unnecessarily complex. }\end{array}$ & 9 & 20 & 26 & 25 & 5 & 85 & 2.96 \\
\hline $\begin{array}{l}34 . \text { I think that I would need } \\
\text { the support of a technical } \\
\text { person to be able to use this } \\
\text { system. }\end{array}$ & 10 & 33 & 20 & 19 & 3 & 85 & 2.67 \\
\hline $\begin{array}{l}36 . \text { I thought there was too } \\
\text { much inconsistency in this } \\
\text { system. }\end{array}$ & 7 & 41 & 26 & 8 & 3 & 85 & 2.52 \\
\hline $\begin{array}{l}38 . \text { I found the system very } \\
\text { cumbersome to use. }\end{array}$ & 8 & 29 & 27 & 17 & 4 & 85 & 2.76 \\
\hline $\begin{array}{l}40 . \text { I needed to learn a lot of } \\
\text { things before I could get going } \\
\text { with this system. }\end{array}$ & 7 & 26 & 18 & 25 & 9 & 85 & 3.04 \\
\hline
\end{tabular}


The final SUS score is also calculated, and the prototype system received a score of 53.96. In general, a SUS score over 50.9 indicates good system usability [39]. Thus, it is considered that the system usability of the prototype system achieved a satisfactory level.

\subsection{Optional Questions Results}

In addition to the questions mentioned above, the survey participants were asked to rate their opinion on the impact of the TRPT proposed activities on the environment before and after they visited the new website. The purpose of the two questions was to evaluate the educational and empowering capability of the system and seek any possible change. As mentioned previously, one of the objectives to engage the public in the EIA process is to create a knowledge base for informing and educating people, and thus, empowerment was proposed as a criterion to evaluate the system. Figure 5 shows the responses. It is noticed that before visiting the prototype system, 54\% of the respondents (46) believed that the TRTP project was not an issue and only $26 \%$ of respondents (22) believed that it had moderate or severe impact on the environment. The mean value 1.81 also suggested that the project was on average considered to have less than a minor impact on the environment. After visiting the website, $80 \%$ of the respondents (68) believed that the project had moderate or severe impact on the environment and the mean value increased to 3.04. This indicates that the new prototype system has successfully served the purpose of educating public users in understanding the selected EIA and promoted their general environmental awareness towards the goal of empowerment.

The survey also asked the subjects if their home address was close to the proposed project activities, if closeness changed their stand about the EIA project and to define closeness. Figure 6 shows that $76 \%$ agreed that closeness changed their position about the project after reviewing the relative location of their home to the project. The rationale is that if a user realizes that an EIA project is in close proximity (e.g., close to the user's house), it is more likely that that they will attach more importance to the project. Moreover, Figure 7 shows that $94 \%$ considered the distance of less than or equal to ten miles as "close", and the mean value is 5.45 miles. This result suggests that the population who is most likely to participate in an EIA is distributed within the radius of ten miles from the proposed project activities. Consequently, if an EIA wants to promote public participation, information dissemination activities should target the public users within this distance.

Figure 5. The responses to Question 30: What was your opinion on the impact of the TRTP proposed activities on the environment? (Coding: 1-Not an issue; 2-Minor impact; 3-Moderate impact; 4-Major impact; 5-Severe impact).

\begin{tabular}{|c|c|c|c|c|c|c|c|c|}
\hline$\#$ & Question & Not an issue & Minor impact & Moderate impact & Major Impact & Severe Impact & Responses,Total Responses & Mean \\
\hline 1 & BEFORE visiting this website & $\underline{47}$ & 17 & $\underline{15}$ & $\underline{6}$ & 1 & 86 & 1.80 \\
\hline 2 & AFTER visiting this website & $\underline{9}$ & $\underline{9}$ & $\underline{42}$ & $\underline{24}$ & $\underline{2}$ & 86 & 3.01 \\
\hline
\end{tabular}

\begin{tabular}{|l|c|c|}
\hline Statistic & BEFORE visiting this website & AFTER visiting this website \\
\hline Mean & 1.80 & 3.01 \\
Standard Deviation & 1.04 & 0.95 \\
Total Responses & 86 & 86 \\
\hline
\end{tabular}


Figure 6. The response to Question 2b-1: Does closeness change your stand about the project?

\begin{tabular}{|c|l|l|c|c|}
\hline$\#$ & Answer & Response & $\%$ \\
\hline 1 & $\underline{\text { Yes }}$ & $\underline{26}$ & $76 \%$ \\
\cline { 2 - 5 } 2 & $\underline{\text { No }}$ & & 8 & $24 \%$ \\
\cline { 2 - 5 } & Total & 34 & $100 \%$ \\
\hline
\end{tabular}

Figure 7. Frequency summary of the responses to Question 2b-2: Define closeness.

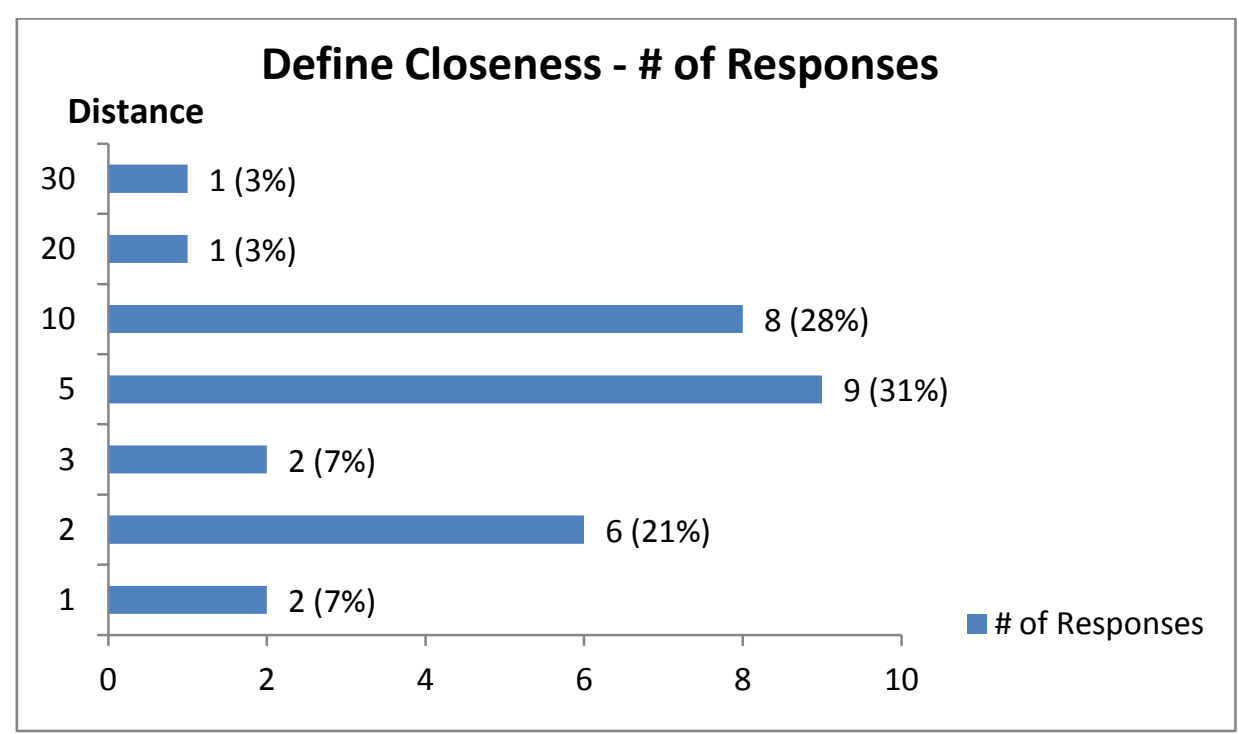

\subsection{Reliability Analysis}

To evaluate whether the questionnaire measured the effectiveness of public participation in a reliable manner, a Cronbach's alpha was calculated to determine the extent to which the scenario questions in the questionnaire were related to each other. Generally, a Cronbach's alpha value above 0.7 is acceptable, and a higher value is considered to have better reliability. The 20 scenario questions in the survey received a Cronbach's alpha value of 0.863 , which suggests a good level of internal consistency.

\section{Limitations and Remarks}

The study has received not only positive feedback, but also raised interesting questions. A few participants expressed concerns about the quality of comments and social media contents collected from the SIPPS prototype system. Comments submitted electronically can be redundant, irrelevant or even malicious. Similarly, the social media contents displayed on the application map viewer are dynamically retrieved from the corresponding social media networks and can contain inappropriate or irrelevant information. A more fundamental problem related to this is the credibility of VGI. VGI content generally consists of three forms: personal opinions (e.g., user comments), objective or factual information (e.g., a photo or video pointing to a particular location), and measurements (e.g., GPS readings) [41]. Although VGI has the strength of collecting local information from a large number of 
citizens, the content generated from collective mapping approaches is often produced by non-experts, and the process usually lacks standardization and coordination of authorities and professionals [21]. The strength is, thus, a double-edged sword that also becomes its major challenge that causes data quality problems [42]. Data quality is compromised when the user-generated content is subjective, unstructured, poorly documented, insufficiently referenced or validated without scientific screening [43]. Data quality can also be impaired due to missing, inconsistent or conflicting values [44]. Therefore, how to integrate participatory mapping techniques especially collective mapping approaches into more formal governance adds another dimension of complexity to the VGI credibility problem. Since collective mapping approaches normally take place when users participate in the data contribution process, strategies are suggested to tackle the complexity challenge from three angles: contributor, data and the contribution process. First, local users or community volunteers can be recruited to screen VGI content and serve as gate-keepers to improve the data quality [45]. Since these contributors are often familiar with the surrounding environment or local events, they are more likely to collaboratively validate the VGI content and identify missing or conflicting data. Moreover, literature suggests that integrating the capability of commenting on VGI submission may improve public understanding, data quality and the knowledge base [21]. The design of the SIPPS framework is aligned with this suggestion. The comment component in SIPPS provides citizens with the ability to submit new comments, review comments, comment on existing posts and rate comments. The survey results also indicated that by providing this interactive functionality, the comment component increased user confidence in the EIA process transparency and willingness to access and share information. It is therefore believed that SIPPS can help overcome the VGI credibility issue and formalize the data collection framework. Nevertheless, it should be noted that this strategy assumes that the recruited contributors are from the local community or have knowledge about the local environments [28]. To validate that they possess the local intelligence, a brief test is suggested to evaluate user knowledge of the related topic or environmental condition [28]. For instance, if the goal of an EIA project is to determine a new power station site in a park, a possible evaluation might involve participants to identify locations of major park features on a map to confirm their familiarity with the area. Note that this research also recognizes that the self-evaluation step could add extra overhead to the existing process and may lessen a user's enthusiasm to participate.

Second, data quality issues in collective mapping may be alleviated by leveraging the power of social media networks and crowdsourcing. Social media networks generate a large number of live feeds on a continuous basis and within a short turnaround time. Although individual feeds can have uncertain quality, data abundance provides an opportunity for grass roots participation to perform cross-validation with considerable VGI content [43]. With this strategy, inputs are aggregated from numerous individuals or sources, and the relevance of the output VGI clusters are evaluated by the contributors in a given context [46]. As a result, more reliable information can be extracted for better data quality. The SIPPS framework responds to this strategy by integrating social media tools in the comment component. The social media tools retrieve live feeds with predefined keywords from social media networks (YouTube, Twitter and Flickr) and display them on a map. By allowing the crowd to review multiple feeds from various sources, SIPPS provides participants with an opportunity to corroborate the information using crowd wisdom. The content retrieved from social media tools can still be irrelevant, and that is why data mining was proposed as part of the SIPPS framework with the 
goal to identify interesting patterns and filter out unwanted or undesirable entries in an automatic fashion. It is also believed that content filtering should be part of the monitoring process of the EIA responsible agencies if they choose to employ a production web system similar to SIPPS to support the EIA process. It is therefore recommended that the EIA agencies delegate an administrator to steward the data contents and manually remove any inappropriate information. Furthermore, a rating mechanism is considered one type of new arbiter of VGI credibility for bottom-up approaches implemented through collaborative efforts [21]. Since VGI content in many cases represents personal opinion or observation rather than scientific data, an objective notion of data quality or accuracy by itself does not seem entirely suitable to assess this type of information [21]. Instead, methods that can reflect people's perception and response to specific scenarios or cultural, political and economic conditions are more appropriate [11]. With regard to the SIPPS prototype, it introduced rating functionality in the comment component for users to examine the more subjective VGI contents. The rating mechanism makes it possible for comments with higher ratings to draw close attention. Collaborative rating on a large scale may also contribute to elimination of inaccurate values. One of the survey respondents suggested that SIPPS include the "Like" functionality (as can be found on Facebook) in the comment component as another dimension for users to examine VGI contents. This suggestion is actually being considered as an area for future work.

In addition to improving the management of contributors and data, the contribution process should be regulated such that the data collection and production chain can operate in a more controllable manner [47]. A series of standards, methods and techniques need to be established to streamline VGI content generation, specify boundaries for data requirements, data ownership, data management and distribution, participant recruitment and address possible responsibility and ethical concerns [21,41,48]. The establishment of this discipline may progress gradually and formalization of governance may limit the freedom of contributors to some extent. To achieve the best outcome, a balance must be maintained between allowing contributor freedom and compliance with necessary specifications [49]. Similarly, a more comprehensive way to deal with VGI content is to assess each given scenario (e.g., an EIA alternative) with data from both authoritative origins and non-expert VGI sources [50].

Another interesting finding that emerged from the survey is the adoption of collaborative mapping techniques into the decision-making process. Evidence from the survey results show that collaborative mapping techniques have the following advantages over other traditional participatory methods in the EIA process: First, the spatial element provided by collaborative mapping has the strength of visualizing geographic features that may not be effectively demonstrated through other interfaces or information sources. Spatial analysis also facilitates early identification of environmental alternatives and problems. Second, findings from the survey (Question 30- What is your opinion about the EIA project before and after visiting the website?) suggested that spatial presentation along with the content sharing and interacting capability can disclose environmental facts and change perceptions on activities and problems. Not only is this valuable to the public in promoting understanding and social learning, but also to EIA decision makers in managing public expectation and mitigating potential conflicts that may happen later in the EIA process. This study identified three major factors that impact the adoption of collaborative mapping techniques in the EIA process: cost, time and outcome. A number of respondents indicated that they would like to know the budget for each EIA alternative and the expense to implement the SIPPS solution. With the current situation of budget cuts and personnel reduction in many 
environmental agencies and public services, it is important that a solution fits into the EIA process with reasonable cost. SIPPS meets this requirement by providing a reusable application template that can be configured and deployed with manageable cost and effort to support similar environmental projects. Although a few commercial-off-the-shelf software products were used in its development, data and map services used in the framework can alternatively be published and hosted through cost-reduced packages designed for organizations, especially environmental and humanitarian institutions.

The time factor is about when to participate and whether a solution will improve time efficiency in EIA. Most survey respondents recognized that SIPPS reduced the time required to participate in the EIA process. From the decision-making side, concern was raised about the timeframe constraint in the EIA public reviewing phase. One respondent acknowledged the benefits of SIPPS in increasing environmental awareness and improving public participation in the EIA scoping phase, but was concerned that the application might make the public reviewing process unnecessarily elongated and delay the final decision process, due to the extra volume of comments that need to be analyzed and additional back-and-forth conversation and negotiation. The study recognized this concern as a possibility and an important factor for the acceptance of collaborative mapping approaches in decision-making, but since the main goal of the study is to improve the effectiveness of public participation in EIA, how to handle the situation is beyond the scope of this research.

Outcome is also considered as a significant factor that influences the adoption of collaborative mapping approaches in EIA decision-making. User feedback in the survey suggested three aspects to cover outcome: uncertainty, diversity and conflict. As previously mentioned, VGI credibility is a major challenge that causes uncertainty. Aggregating crowd wisdom is able to help verify general information and enhance information provided by authorities. Reducing data fluctuation between good and bad will minimize uncertainty and increase the confidence of decision makers in undertaking a VGI solution. Furthermore, one of the fundamental goals of involving the public in EIA is to empower marginalized groups and establish a more equitable decision structure across the distribution of political power [51]. Ideally, the EIA participatory process should account for common views shared by individuals or representatives of various groups [4]. Therefore, diversity becomes a consideration for decision makers to accept collaborative approaches. Collaborative mapping approaches, on one hand, provide more flexibility by releasing people from spatial and temporal constraints of attending physical meetings (Feedback in Questions 23 and 24 confirmed this finding); on the other hand, VGI contents are often presented through a web-based interface, which can create a participation barrier for people who lack computer literacy and Internet access. This limitation is known as the "digital divide" [52]. In terms of conflict, a desirable participatory method should support decision makers to prioritize concerns, communicate outcomes and manage conflicts. Before decisions are made on EIA projects, risk and impact analysis of each alternative needs to be conducted. VGI content that reflects local intelligence and creativity not only assists decision makers in identifying alternatives, but also allows them to explore various options and discover better solutions. In SIPPS, this is realized by the spatial feature editing function and comment responding capability. Once a decision is made or project activities are under development, the progress and outcome must be communicated to the public. Collaborative mapping approaches are capable of distributing the information in a timely manner to a large population via the web and the mobile platform. In SIPPS, a map viewer on both the web and the mobile interface is provided for decision makers to inform and collect feedback from the public. The 
social and political interaction enabled by collaborative mapping approaches between decision makers and the public also represents a more proactive way to avoid and resolve conflicts, because it demonstrates a sense of ownership on issues, a traceable sequence to address concerns and mutual understanding of legal requirements, values, perceptions and interest of involved parties.

Besides the above challenges, it is recognized that the study sample size is limited and some of the inferences discovered from the research sample may not be generalized to a larger population. The results can be skewed towards younger, more educated people who are computer literate. Responses indicated that the older generation, who may not have computer skills and access to social media tools, were usually more concerned about the impacts of EIA activities (especially the impact on health and safety) and, thus, more likely to participate in EIAs.

Lastly, while the study produced a conceptual framework and a prototype system to improve the effectiveness of public participation in EIA, it does not recommend completely abandoning the traditional methods. One respondent pointed out that she would use both the traditional methods and a website, like the one designed in this research, to raise her voice if an EIA was really concerning her. Therefore, a combination of both instruments may generate a better outcome and benefit the citizens to the greatest extent.

\section{Contributions and Conclusions}

This study presented a five-component conceptual framework, with the goal to improve the effectiveness of public participation in the EIA process. A web-based spatially intelligent public participation system (SIPPS) was designed and implemented as a prototype to assess the concept. Survey questionnaires and user scenarios were used to collect user feedback and evaluate the system. Results have shown that compared to the traditional methods, SIPPS was able to improve multiple effectiveness criteria, such as information accessibility, collaborative and sharing capability, willingness to participate and transparency. It was also successful in promoting user environmental awareness and improving system usability.

The major contribution of this research is three-fold: First, it uniquely combined GIS, VGI, social media tools, data mining and mobile technology from multiple dimensions in designing the conceptual framework to improve public participation in the EIA process. This has not been found in any of the previous literature reviewed in the information systems or environmental academic community. Second, the conceptual framework and the prototype system designed in this study are generic enough to be utilized as a template to benefit other environmental projects similar to the selected case study. The conceptual framework is scalable and the application template can be configured and deployed with reasonable cost and effort to meet the needs of local governments and agencies in enhancing public participation in other environmental projects. Third, from the empowerment perspective, not only will the framework and the system serve as an instrument to educate the public in understanding a particular EIA project, but it will also contribute to the formulation of a collective knowledge base regarding public participation in policy making, enhancing trust and, ultimately, the development of a sustainable society. 


\section{Acknowledgments}

We would like to thank the support received from the following CGU faculty members: Hal Nelson, Lorne Olfman, June Hilton and Tom Horan.

\section{Conflict of Interest}

The authors declare no conflict of interest.

\section{References}

1. Del Furia, L.; Wallace-Jones, J. The effectiveness of provisions and quality of practices concerning public participation in EIA in Italy. Environ. Impact Asses. 2000, 20, 457-479.

2. Qin, X.; Tao, C. Analysis of Public Constructoin and the Use of Envrionmental Information. In Proceedings of International Conference on Mechanic Automation and Control Engineering (MACE), Wuhan, China, 26-28 June 2010; pp. 1948-1951.

3. Lowndes, V.; Pratchett, L.; Stoker, G. Trends in public participation: Part 1-Local government perspectives. Public Admin. 2001, 79, 205-222.

4. Gonzalez, A.; Gilmer, A.; Foley, R.; Sweeney, J.; Fry, J. Technology-aided participative methods in environmental assessment: An international perspective. Comput. Environ. Urban 2008, 32, 303-316.

5. Harris, T.; Weiner, D. GIS and Society: The Social Implications of How People, Space, and Environment are Represented in GIS. Available online: www.ncgia.ucsb.edu/Publications/ Tech_Reports/96/96-7.PDF (accessed on 13 January 2013).

6. Sieber, R. Public participation geographic information systems: A literature review and framework. Ann. Assoc. Am. Geogr. 2006, 96, 491-507.

7. Al-Kodmany, K. GIS and the Artist: Shaping the Image of a Neighbourhood in Participatory Environmental Design. In Community Participation and Geographic Information Systems, 1st ed.; Craig, W.J., Harris, T.M., Weiner, D., Eds.; Taylor and Francis: New York, NY, USA, 2002; pp. 320-329.

8. Bojórquez-Tapia, L.; Díaz-Mondragón, S.; Ezcurra, E. GIS-based approach for participatory decision making and land suitability assessment. Int. J. Geogr. Inf. Sci. 2001, 15, 129-151.

9. Kingston, R.; Carver, S.; Evans, A.; Turton, I. Web-based public participation Geographical Information Systems: An aid to local environmental decision-making. Comput. Environ. Urban 2000, 24, 109-125.

10. Haklay, M.E. Public access to environmental information: Past, present and future. Comput. Environ. Urban 2003, 27, 163-180.

11. Stefanidis, A.; Crooks, A.; Radzikowski, J. Harvesting ambient geospatial information from social media feeds. Environ. Manage. 2012, 49, 816-832.

12. Yap, L.F.; Bessho, M.; Koshizuka, N.; Sakamura, K. User-Generated Content for Location-Based Services: A Review. In Virtual Communities, Social Networks and Collaboration; Lazakidou, A.A., Ed.; Springer Science: New York, NY, USA, 2012; Vo1ume 15, p. 163. 
13. Howe, J. The Rise of Crowdsourcing. Available online: http://www.wired.com/wired/archive/ 14.06/crowds.html (accessed on 13 January 2013).

14. Brabham, D.C. Crowdsourcing as a model for problem solving: An introduction and cases. Int. J. Res. New Media Technol. 2008, 14, 75-90.

15. Committee on New Research Directions for the National Geospatial-Intelligence Agency; Mapping Science Committee; Board on Earth Sciences and Resources; Division on Earth and Life Studies. Workshop on New Research Directions for the National Geospatial-Intelligence Agency, 1st ed.; The National Academies Press: Washington, DC, USA, 2010; pp. 2-3. Available online: http://www.nap.edu/catalog.php?record_id=12964 (accessed on 13 January 2013).

16. Goodchild, M.F. NeoGeography and the nature of geographic expertise. J. Locat. Based Serv. 2009, 3, 82-96.

17. Núñez-Redó, M.; Díaz, L.; Gil, J.; González, D.; Huerta, J. Discovery and Integration of Web 2.0 Content into Geospatial Information Infrastructures: A Use Case in Wild Fire Monitoring. In Proceedings of the IFIP WG 8.4/8.9 International Cross Domain Conference on Availability, Reliability, and Security for Business, Enterprise and Health Information Systems, Vienna, Austria, 22-26 August 2011; Tjoa, A.M., Oqirchmayr, G., You, I., Xu, L., Eds.; Springer-Verlag: Vienna, Austria, 2011; pp. 50-68.

18. Goodchild, M.F. Citizens as voluntary sensors: Spatial data infrastructure in the world of Web 2.0. Int. J. Spat. Data Infrastruct. Res. 2007, 2, 24-32.

19. Tulloch, D.L. Many Many Maps: Empowerment and Online Participatory Mapping. Available online: http://firstmonday.org/htbin/cgiwrap/bin/ojs/index.php/fm/article/view/1620/1535 (accessed on 13 January 2013).

20. Turner, A.J. Introduction to Neogeography; O’Reilly Media: Sebastopol, CA, USA, 2006; pp. $2-3$.

21. Flanagin, A.J.; Metzger, M.J. The credibility of volunteered geographic information. GeoJournal 2008, 72, 137-148.

22. Belimpasakis, P.; Saaranen, A. Sharing with people: A system for user-centric content sharing. Multimed. Syst. 2010, 16, 399-421.

23. Daz, L.; Granell, C.; Gould, M.; Huerta, J. Managing user-generated information in geospatial cyber infrastructures. Future Gener. Comput. Syst. 2011, 27, 304-314.

24. Creighton, J. The Public Participation Handbook: Making Better Decisions through Citizen Involvement, 1st ed.; Jossey-Bass: San Francisco, CA, USA, 2005; p. 244.

25. Ho, S.; Rajabifard, A. Learning from the Crowd: The Role of Volunteered Geographic Information in Realising a Spatially Enabled Society. In Proceedings of GSDI 12 World Conference-Realising Spatially Enabled Societies, Singapore, 19-22 October 2010.

26. Werts, J.D.; Mikhailova, E.A.; Post, C.J.; Sharp, J.L. An integrated WebGIS framework for volunteered geographic information and social media in soil and water conservation. Environ. Manage. 2012, 49, 816-832.

27. Danielsen, F.; Burgess, N.D.; Jensen, P.M.; Pirhofer-Walzl, K. Environmental monitoring: The scale and speed of implementation varies according to the degree of peoples involvement. J. App. Ecol. 2010, 47, 1166-1168.

28. Seeger, C.J. The role of facilitated volunteered geographic information in the landscape planning and site design process. GeoJournal 2008, 72, 199-213. 
29. Kelly, M.; Tuxen, K.; Kearns, F. Geospatial informatics for management of a new forest disease: Sudden oak death. Photogramm. Eng. Remote Sensing 2004, 70, 1001-1004.

30. Eick, C.; Vaezian, B.; Jiang, D.; Wang, J. Discovery of Interesting Regions in Spatial Datasets Using Supervised Clustering. In Proceedings of the 10th European Conference on Principles and Practice of Knowledge Discovery in Databases, Berlin, Germany, 18-22 September 2006; pp. 127-138.

31. Rzhetsky, A.; Seringhaus, M.; Gerstein, M.B. Getting started in text mining: Part two. PLoS Comput. Biol. 2009, 5, doi: 10.1371/journal.pcbi.1000411.

32. Maue, P.; Schade, S. Data integration in the geospatial semantic web. J. Cases Inf. Technol. 2009, $11,100-122$.

33. Gao, L.; Chang, E.; Han, S. Powerful tool to expand business intelligence: Text mining. World Acad. Sci. Eng. Technol. 2005, 8, 110-115.

34. Glasson, J.; Therivel, R.; Chadwick, A. Introduction to Environmental Impact Assessment, 3rd ed.; Routledge: New York, NY, USA, 2005; p. 127.

35. Bishop, P.; Davis, G. Mapping public participation in policy choices. Aust. J. Publ. Admin. 2006, 61, 14-29.

36. Pring, G.; Noe, S.Y. The Emerging International Law of Public Participation Affecting Global Mining, Energy and Resource Development. In Human Rights in Natural Resource Development: Public Participation in the Sustainable Development of Mining and Energy Resources, 1st ed.; Zillman, D.M., Lucas, A., Pring, G., Eds.; Oxford University Press: New York, NY, USA, 2002; pp. 11-76.

37. De Steiguer, J.E. Evaluating the Effectiveness of Multi-Criteria Decision Models for Improving Public Participation; Accession No. 0194153. Available online: http://www.reeis.usda.gov/web/ crisprojectpages/194153.html (accessed on 29 July 2012).

38. Pischke, F.; Cashmore, M. Decision-oriented environmental assessment: An empirical study of its theory and methods. Environ. Impact Asses. 2006, 26, 643-662.

39. Bangor, A.; Kortum, P.T.; Miller, J.A. An empirical evaluation of the System Usability Scale (SUS). Int. J. Human-Comput. Interact. 2008, 24, 574-594.

40. Cutter, S.L.; Mitchell, J.T.; Scott, M.S. Revealing the vulnerability of people and places: A case study of Georgetown County, South Carolina. Ann. Assn. Amer. Geogr. 2000, 90, 713-737.

41. Gouveia, C.; Fonseca, A. New approaches to environmental monitoring: The use of ICT to explore volunteered geographic information. GeoJournal 2008, 72, 185-197.

42. Elwood, S. Volunteered geographic information key questions, concepts and methods to guide emerging research and practice. GeoJournal 2008, 72, 133-135.

43. Schade, S.; Díaz, L.; Ostermann, F.; Spinsanti, L.; Luraschi, G.; Cox, S.; Nuñez, M.; de Longueville, B. Citizen-based sensing of crisis events: Sensor web enablement for volunteered geographic information. Appl. Geomat. 2011, 5, 3-18.

44. Yanenko, O.; Schilieder, C. Enhancing the Quality of Volunteered Geographic Information: A Constraint-Based Approach. In Bridging the Geographic Information Sciences; Gensel, J., Josselin, D., Vandenbroucke, D., Eds.; Springer-Verlag: Berlin/Heidelberg, Germany, 2012; pp. 429-446. 
45. Bishr, M.; Mantelas, L. A trust and reputation model for filtering and classifying knowledge about urban growth. GeoJournal 2008, 72, 229-237.

46. Mummidi, L.; Krumm, J. Discovering points of interest from users' map annotations. GeoJournal 2008, 72, 215-227.

47. Lee, V. Volunteer Monitoring: A Brief History. Available online: http://water.epa.gov/type/rsl/ monitoring/upload/2004_10_13_monitoring_volunteer_newsletter_volmon06no1.pdf (accessed on 2 April 2013).

48. De Longueville, B.; Annoni, A.; Schade, S.; Ostländer, N.; Whitmore, C. Digital Earth's nervous system for crisis events: Real-time sensor web enablement of Volunteered Geographic Information. Int. J. Digital Earth 2010, 3, 242-259.

49. Girres, J.-F.; Touya, G. Quality assessment of the French OpenStreetMap dataset. Trans. GIS 2010, $14,435-459$.

50. Connors, J.P.; Lei, S.; Kelly, M. Citizen science in the age of Neogeography: Utilizing volunteered geographic information for environmental monitoring. Ann. Assn. Amer. Geogr. 2012, 102, 1267-1289.

51. O'Faircheallaigh, C. Public participation and environmental impact assessment: Purpose, implications, and lessons for public policy making. Environ. Impact Asses. 2010, 30, 19-27.

52. Oden, M.D.; Lentz, R.G. Digital divide or digital opportunity in the Mississippi delta region of the US. Telecommun. Policy 2001, 25, 291-313.

(C) 2013 by the authors; licensee MDPI, Basel, Switzerland. This article is an open access article distributed under the terms and conditions of the Creative Commons Attribution license (http://creativecommons.org/licenses/by/3.0/). 